\title{
Guimarães Rosa e o jornalismo
}

\author{
Gustavo Castro' \\ https://orcid.org/0000-0001-7126-6947 \\ Andrea Jubé \\ https://orcid.org/0000-0003-0987-2502 \\ I - UNB. \\ Brasília (DF), Brasil
}

Resumo: Jornalismo e Literatura. Guimarães Rosa. Biografia. Este artigo insere-se no conjunto de estudos e pesquisas denominado "Perfil biográfico de João Guimarães Rosa (1908-1967)", projeto desenvolvido pelo Grupo Siruiz - Estudos Comunicação e Produção Literária (CNPq/ UnB). Trata-se de um recorte específico da relação do escritor mineiro com a imprensa, analisando suas ligações com repórteres, editores e empresários de comunicação, além de sua aversão a entrevistas, entre os anos de 1947 e 1967. Interessam aqui as aparições, presenças e relações de proximidade que o autor mantinha e cultivava com a imprensa em seu tempo.

Palavras-Chave: jornalismo e literatura; Guimarães Rosa; biografia.

Abstract: Guimarães Rosa and journalism - This article is part of a series of studies and researches entitled "Biographical Profile of João Guimarães Rosa (1908-1967)", a project developed by the Siruiz Group - Studies on Communication and Literary Production (CNPq / UnB), and focuses on the writer's relationship with the press, analyzing his connections with reporters, editors and media outlet's owners, in addition to his aversion to interviews, between the years of 1947 and 1967. The focus here is his presence and appearances in the media and the writer's close association with the press in his time.

Keywords: journalism and literature; Guimarães Rosa; biography.

\section{Introdução - imprensa versus eternidade}

Neste texto pretendemos investigar as proximidades de Guimarães Rosa com o campo jornalístico. Entendemos aqui por "proximidade" o coexistir de uns com os outros mediante "identificações" ou como campo de atrações recíprocas por meio de "incorporações, invasões, imbricações, reflexões e ressonâncias" (SLOTERDIJK, 2016, p. 90), assim como as interações em "espaços íntimos partilhados, cossubjetivos e interinteligentes, dos quais só fazem parte grupos diádicos" (ibidem). 
A proximidade do escritor mineiro com o campo jornalístico não foi, a nosso ver, devidamente tratada por Walnice Nogueira Galvão em seu ensaio Página de jornal, página de livro (2008). Desde 1972, Galvão (professora titular de teoria literária e literatura comparada da USP), dedica-se a compreender a obra de Guimarães Rosa em seus diversos matizes. O pioneirismo, a argúcia e a profundidade das análises de Galvão, com a publicação de vários livros (GALVÃO, 1978; 1986; 2000; 2008) sobre o escritor mineiro, não foram suficientes, no entanto, para aprofundar criticamente a relação de Rosa com o jornalismo e o campo da comunicação.

A partir de minuciosa pesquisa no Fundo Guimarães Rosa', no Instituto de Estudos Brasileiros (IEB-USP), confrontada com pesquisas secundárias e complementares em acervos de hemerotecas de bibliotecas públicas, vimos que, ao contrário da interpretação de Galvão (2008), para quem a relação de Guimarães Rosa com o jornalismo era algo em que ele "jamais se considerou à vontade", que executou "sem regularidade e de modo avulso" (GALVÃO, 2008, p. 218), Rosa adotou uma postura ambígua, com interesses, proximidades e distanciamentos em relação a este ofício.

Verificamos que, a certo ponto de sua vida, Rosa não só esteve próximo, como bastante ligado e à vontade no campo jornalístico, tendo inclusive explorado técnicas e fundamentos dialógicos (e interativos) referentes a essa prática na construção de suas histórias. Ele também fez de vários jornalistas seus conselheiros e até promotores (marqueteiros) de sua obra, sendo que alguns deles se tornaram seus melhores amigos pessoais. Rosa convivia com eles semanalmente, ao longo de anos a fio, como no caso de Álvaro Lins (1912-1970), Franklin de Oliveira (1916-2000) e Josué Montello (1917-2006), ou em relações esparsas, mas próximas, como no caso de Pedro Bloch (1914-2004), José Carlos de Macedo Soares (1883-1968), Joel Silveira (1918-2007), Antonio Olinto (19192009), Assis Chateaubriand (1892-1968) e João Neves da Fontoura (1887-1963).

Notamos em nossa pesquisa que o escritor mineiro conviveu com a prática jornalística e com profissionais da imprensa com regularidade crescente, e não "sem regularidade e de modo avulso", como observou Galvão. Enquanto preferia evitar repórteres, estimava o convívio com chefes-de-redação, editores, editorialistas e empresários do meio. ${ }^{2}$ Podemos dizer que Rosa estava atento às rotinas produtivas, ao savoir-faire, às pautas, às notícias falsas ou distorcidas. Ele acompanhava com atenção as notícias plantadas pelo regime nazista, no tempo em que morou em Hamburgo (1938-1942), conforme pode ser verificado em seu "Diário de Guerra" ${ }^{3}$, como é chamado seu caderno de anotações sobre o cotidiano da Segunda Guerra, em Hamburgo, na Alemanha.

1 Fundo JGR-IEB/USP. Acervo que conta com mais de nove mil documentos pertencentes aos escritor mineiro, além de sua biblioteca pessoal.

2 Como o próprio Macedo Soares (financiador de O Imparcial e do Diário Carioca, dirigidos por seu irmão, José Eduardo) e Assis Chateubriand (dos Diários Associados).

3 O chamado "Diário de Guerra" de Rosa foi organizado por Eneida Maria de Souza, Reinaldo Marques e George Otte, professores do Programa de Estudos Literários da UFMG. Os professores estabeleceram uma organização do texto, com notas explicativas, introdução e tradução de expressões em alemão retiradas da imprensa por JGR e coladas em seu diário. O manuscrito em fotocópia encontra-se no Arquivo Henriqueta Lisboa, no Acervo de Escritores Mineiros, da UFMG. 
Os dados coletados em nosso levantamento mostram que os laços de Rosa com a imprensa formam faceta pouco conhecida e pouco investigada em sua biografia, por isso pretendemos explorá-la neste artigo mediante a articulação de dados de pesquisa recolhidos, entre outros lugares, ${ }^{4}$ no Instituto de Estudos Brasileiros (IEB/USP), articulados em três frentes de trabalho: 1) a relação de JGR com os poderes organizacionais, sintetizados aqui na palavra imprensa; 2) a relação de JGR com editores e repórteres, na qual tratamos de sua aversão a entrevistas; 3) a relação de jornais e revistas com JGR. Trabalharemos o conjunto dos dados não necessariamente nesta ordem, mas articulados, no esforço de organizar a massa de informações presente no Fundo JGR em dois pontos convergentes: 1) a percepção ética, estética e estratégica de Rosa para com a prática jornalística, a imprensa e seus atores e 2) as marcas e as presenças do jornalismo em sua literatura.

Walnice Nogueira Galvão definiu Guimarães Rosa, em seu estudo Página de jornal, página de livro, como um "tipo refratário": "para quem o jornalismo não tem a menor importância, é aleatório e inteiramente subjugado à literatura" (GALVÃO, 2008, p. 227). Para a grande estudiosa roseana, há apenas um "único caso" de colaboração sistemática, com o jornalzinho de médicos Pulso, que resultaria no livro Tutameia - Terceiras estórias (ibidem, p. 218). No entanto, ao se analisar detalhadamente as presenças e as proximidades de Rosa no e com o jornalismo, devemos discordar desta afirmação. A assertiva de Galvão contrasta com os dados levantados no Fundo JGR-IEB/USP. É bem verdade, como salienta ela, que Rosa tinha o hábito de transpor para livro histórias que publicava primeiro em jornais ou revistas. Em nossa contabilidade, durante vinte anos (1947-1967), o escritor mineiro publicou nada menos do que 122 histórias - contos, crônicas, poemas e duas "reportagens poéticas" (na definição de Paulo Rónai) -, nos seguintes periódicos: O Globo, Pulso, Correio da Manhã, O Jornal (RJ), O Cruzeiro, Manchete, Senhor, Letras e Artes (suplemento do jornal A Manhã), Diário de Minas (MG), Folha da Manhã (SP), O Estado de S. Paulo (SP) e Jornal de Letras (RJ).

Esse volume de 122 histórias circulou primeiro na imprensa, sendo depois incorporado aos seguintes livros: Primeiras estórias (1962) e Tutameia (Terceiras estórias) (1967), que publicou em vida; e Estas estórias (1969) e Ave, Palavra (1970)5 ${ }^{5}$, que são edições póstumas. Constatamos que essas 122 histórias foram publicadas 136 vezes nos jornais e revistas, se considerarmos as republicações. O número de 122 histórias sobe para 126, se levarmos em conta as primeiras publicações que remontam a 1929 e 1930 em O Cruzeiro (RJ) e O Jornal (RJ), textos que jamais foram incluídos em livros. ${ }^{6}$

4 Como no arquivo da Hemeroteca da Biblioteca Nacional (BN), nos Cadernos de Literatura Brasileira do Instituto Moreira Salles, teses de doutorado e obras relacionadas.

5 É emblemático que antes de optar pelo nome definitivo Ave, Palavra, o escritor - que às vezes incorporava o personagem repórter -, pensou em atribuir à obra o título ... Reportagens. Diz Paulo Rónai que as outras opções eram: "Azulejos Amarelos, Conversas com Tempo, Sortidos e Retalhos, Desconexões, Via e Viagens, Contravazios, Moxinifada, Almanaque, Poemas do Esporádico, Exercícios de Saudade, Meias-Estórias e Oficina Aberta" (RONAI in: ROSA, 2009a, p. 19)

6 O Mistério de Highmore Hall (7/12/1929), Chronos kai Anagke (Tempo e destino) (21/6/1930) e Caçadores de camurças (12/7/1930), na revista O Cruzeiro (RJ), e Makiné (9/2/1930), em O Jornal (RJ) 
Desses 122 textos publicados entre 1947 e 1967, outros três também nunca entraram em livros: "Os doces" [7/6/1953 e 1/6/1954, jornal A Manhã, suplemento Letras e Artes]; "O inverso afastamento" [15/7/1961, jornal O Globo] e "Rogo e aceno" [29/7/1967, jornal Pulso]. Ao final, entre exclusões e incorporações de histórias, somam-se 110 histórias publicadas na imprensa entre 1947 e 1967, que depois foram para os quatro livros acima citados. Outra discordância em relação a Galvão está no fato de ela acreditar que o "único caso de colaboração sistemática" tenha sido "com o jornalzinho de médicos Pulso" (ibidem, p. 218), o que também não é verdade. De janeiro a agosto de 1961, o escritor, religiosamente, enviou um conto, crônica ou poema para publicação aos sábados no jornal O Globo, na coluna do amigo e escritor Antônio Olinto. Somente quatro anos depois começou sua colaboração com o jornal Pulso, que durou de maio de 1965 a julho de 1967. Neste jornal, ele dividia uma coluna semanal com Carlos Drummond de Andrade.

Incomum nos dias de hoje, o "jornal médico" Pulso era editado no Rio de Janeiro, sendo publicado pelo laboratório Sidney Ross, fabricante de medicamentos leves, como Melhoral, Sonrisal e Sal de Frutas Andrews. Sob a coordenação do médico Roberto de Souza Coelho e do jornalista Elísio Valverde - que havia sido editor do Diário de Minas -, tinha circulação nacional, sendo distribuído a consultórios médicos e farmácias. Somente no Pulso, Rosa publicou 56 histórias de uma página e $\mathrm{meia}^{7}$, quarenta delas depois reunidas em Tutameia. Estas informações, assim como a passagem da narrativa em jornal para a publicação em livro, invariavelmente com pequenas alterações de forma, conferem, a nosso ver, necessidade de problematização da relação de Guimarães Rosa com a imprensa.

Cabe também aqui a problematização da noção de "eternidade", bastante cara a Guimarães Rosa, que justificava seu desinteresse pelo jornalismo praticado no dia a dia, com o argumento de "provisório" e "transitório" (ROSA, 1963, p.23). A necessidade de problematização da noção de "eternidade" deve-se ao fato concreto de que textos considerados obras-primas tenham circulado primeiro em periódicos, para somente depois ganhar as páginas dos livros. Ou seja: textos que ele imaginava terem sido escritos para a "eternidade", aparecem primeiro sob a forma "banal" (ROCHE, 2000, p.281) do periódico, em jornais diários ou revistas mensais, vendidos nas bancas ou distribuídos para assinantes.

A partir deste ponto, devemos considerar deficitária (ou, no mínimo, questionável) a definição de "eternidade" de Guimarães Rosa, assim como sua noção de "banal". Deficitária porque contraditória. Na quantidade de textos considerados clássicos, publicados primeiro em jornais e revistas, está incluído, entre outros, A terceira margem do rio (depois transformado em longa-metragem por Nelson Pereira dos Santos, em 1994, e em música de Milton Nascimento, em 1990), que apareceu no jornal O Globo, em abril de 1961, para mais tarde, ganhar as páginas de Primeiras Estórias (1962). Outro clássico:

7 Rosa confidenciou que buscava há anos solução para histórias que já estavam em sua cabeça. Ele explicou que foi na forma curta, abreviada, que encontrou o desfecho para essas histórias: "porquanto os temas de alguns dos contos andavam-me sem solução na cabeça, uns há cerca de 20 anos, até que, só nesta forma curta, forçada pela limitação de espaço, encontraram como compor-se" (ROSA apud Cadernos de Literatura Brasileira, 2006, p. 52). 
Meu tio o lauaretê, célebre conto em que um homem metamorfoseia-se em onça, veio à luz primeiro na revista Senhor, em março de 1961, para depois ser incluído em Estas estórias (póstumo, 1969). Os dados colhidos no Fundo JGR-IEB/USP contestam e questionam o fato de ele não se considerar "à vontade" no jornalismo. Parecia tão à vontade que passou a cobrar quantias altíssimas quando queriam publicar seus textos em periódicos.

\section{Amigos jornalistas e o relacionamento com os meios}

Como sabemos, era comum que escritores brasileiros trabalhassem em jornais em busca de um meio de subsistência, visibilidade e da consolidação de sua arte. Rosa, no entanto, não conheceu a experiência de repórter, articulista, editor ou cronista contratado dos jornais e revistas para dar expediente nas redações. Conhecia, no entanto, a rotina produtiva; chegou a telefonar para as redações sugerindo pautas ${ }^{8}$; acompanhava semanalmente as atividades de Álvaro Lins e Franklin de Oliveira, seus amigos mais íntimos e próximos, ambos jornalistas; tinha também conversas com os irmãos José e João Condé sobre a conjuntura editorial (e cultural) do Rio de Janeiro e de São Paulo; além de João Neves da Fontoura, amigo e ex-chefe no Ministério das Relações Exteriores, um dos editorialistas do jornal $O$ Globo.

Por temperamento, Rosa não era o tipo que se adequava ao ritmo de produção de notícias, no entanto, procurava escrever ${ }^{9}$ a seu modo, em casa ou no Itamaraty, sendo que a sua experiência (da obrigação de entregar os textos no prazo imposto pelo veículo) se deu unicamente com O Globo e Pulso, como vimos. Rosa estava sempre atento às páginas da imprensa por três motivos: 1) contextualização da geopolítica nacional e internacional; 2) divulgação de seu trabalho, sempre citado e comentado, seja em matérias, seja nas notinhas literárias, as quais Rosa pacientemente recortava e colava em folhas avulsas ou em cadernos e, 3) como busca de lucro e ganhos financeiros na negociação de seus textos com editores.

Vale registrar (relembrar) que a postura de Rosa em relação a seu trabalho, diante de jornais e revistas, está quase sempre associada à sua busca de alguma remuneração financeira. Nisto, começou bem cedo. Em sua tese de doutorado, Mônica Fernanda Rodrigues Gama (2013) salienta que, ainda como estudante de Medicina (1925-1930), Rosa enviou contos ao concurso da revista O Cruzeiro, em função, segundo ele próprio confessou, do dinheiro do prêmio. O mesmo aconteceu com o livro de poesia Magma, com o qual venceu o prêmio (em dinheiro) dado pela Academia Brasileira de Letras (ABL),

8 Na crônica "O homem de Santa Helena", publicada em Letras e Artes, suplemento do jornal A Manhã (RJ), em 3/5/1953, e incluída em Ave, palavra, Rosa relata que telefonou para a redação de um jornal sugerindo que entrevistassem o brasileiro morador da ilha onde Napoleão foi exilado. Otto Lara Resende também relata que Rosa pediu-lhe que desse uma nota no Jornal do Brasil sobre sua posse na Academia Brasileira de Letras (RESENDE, 2017).

9 É preciso reconhecer que Rosa não considerava o hábito de registrar as informações em cadernetas atributo dos repórteres, mas dos escritores. Como escritor, sustentava que por dever de ofício deveria manter um caderninho à mão para registro frequente de cenas, flagrantes ou qualquer fato pitoresco ou expressão inusitada que lhe servisse de inspiração. 
em 1936. Depois de Sagarana (1946), Rosa voltou a publicar em periódicos, em 1947, "motivado ou não pela questão financeira, que era evidentemente um incentivo para muitos escritores" (GAMA, 2013, p. 230).

Em entrevista à revista Realidade (1967), Paulo Francis revelou que Guimarães Rosa cobrou "uma fortuna" para se tornar colaborador permanente da revista Senhor. $\mathrm{Na}$ reportagem veiculada quatro meses antes da morte do escritor, Francis relembrou quando ele e o fundador da publicação, Nahum Sirotsky, decidiram perguntar a Rosa se ele tinha um original pronto para a revista. Havia receio, porque consideravam Rosa um "artista" e não um "profissional do jornalismo, a quem se encomenda trabalho" (FRANCIS apud PEREIRA, 1967). A resposta do escritor na ocasião os surpreendeu. Rosa disse: "Não tenho, mas escrevo um para vocês. Quanto vocês pagam?" (Ibidem). Francis relembra que, dias depois, Rosa apareceu na redação com um conto inédito: tratava-se de $A$ simples e exata estória do burrinho do comandante, publicado na edição de abril de 1960 da revista Senhor, depois transposto para Estas estórias (1969).

Francis relatou que foram dias de negociação até Nahum Sirotisky ceder e aceitar pagar os 40 mil cruzeiros velhos pelo conto. Ele observa que o valor era "uma fortuna" para esse tipo de matéria, mas o fundador da revista cedeu ao "cansaço" e ao "prestígio" do escritor. Francis complementou que Rosa teria se encantado com o "público à sua disposição" e propôs tornar-se colaborador permanente. "Foi difícil resistir à sua investida trabalhista e terminamos docemente derrotados" (FRANCIS apud PEREIRA, 1967, p. 60), relembrou Francis na reportagem. Passado algum tempo, os editores foram obrigados a, diplomaticamente, informar ao escritor que os leitores queriam mais do que apenas histórias "regionais". Francis relatou que Rosa prontificou-se a escrever sobre qualquer assunto, "desde que recebesse os 40 mil cruzeiros"10 (Ibidem).

Passou-se quase um ano até que a segunda história fosse publicada: Meu tio, o lauaretê, em março de 1961. Depois, em dezembro do mesmo ano, Rosa enviou à Senhor uma história de Natal: O burro e o boi no presépio, que depois foi para as páginas de Ave, palavra. No total, foram sete contos escritos para a revista Senhor entre 1960 e $1962 .{ }^{11}$ Quem observou o apreço de Rosa pela remuneração foi Otto Lara Resende, na crônica que escreveu sobre o amigo:

Gostava confessadamente de dinheiro. Disse-me que o dinheiro não se destina a comprar coisas, mas, sim, as coisas é que são feitas para se transformar em

10 Segundo a série histórica consultada no site da Seção de São Paulo da Ordem dos Advogados do Brasil (OAB-SP), o valor do salário mínimo nos primeiros meses de 1960 - quando Rosa publicou a primeira estória em Senhor - era 6 mil cruzeiros. Portanto, o escritor cobrou o equivalente a 6,6 salários mínimos da época. Multiplicandose pelo valor atual, de R\$937, podemos afirmar que o valor cobrado pelo escritor pelas estórias criadas para a revista era de aproximadamente $\mathrm{R} \$ 6,1 \mathrm{mil}$.

11 Os sete contos escritos por encomenda da revista Senhor, a 40 mil cruzeiros cada um, e tendo sido todos republicados em livros, foram: A simples e exata estória do burrinho do comandante (abril/1961), Meu tio o lauaretê (março/1961), e A estória do homem do pinguelo (março/1962) publicados em Estas estórias. O burro e o boi no presépio (dezembro/1961), publicado em Ave, palavra; Substância (abril/1962), Partida do audaz navegante (maio/1962) e Nenhum, nenhuma (agosto/1962), publicados em Primeiras estórias. 
dinheiro. Viajava com passagens e hospedagem pagas e fazia questão de regressar com algum dinheiro no bolso. Quando se cogitou seu nome para membro do júri do /l Concurso Nacional de Romance Walmap, ao lado de Jorge Amado e Antônio Olinto, disse que se não fosse remunerado não aceitava. Para ele, o prêmio deveria ser distribuído entre os membros do júri, ao premiado bastava a honra da láurea e a publicação da obra (RESENDE, 2017, posição 3013).

Ele também recorria à ajuda de amigos para administrar sua imagem e controlar eventuais excessos ou distorções que detectava em publicações sobre si. Amigo muito próximo de jornalistas-escritores comandantes de editorias de veículos em que publicou, ou de colunistas literários, a exemplo de Álvaro Lins ${ }^{12}$, Rosa também era próximo de Franklin de Oliveira, Josué Montello, Antônio Olinto, Pedro Bloch, Otto Lara Resende, entre outros. O casal Rosa-Aracy mantinha relações íntimas com os casais Franklin-Lígia; Montello-Ivone; Álvaro-Heloísa. Essas relações variavam de almoços semanais, geralmente aos finais de semana, a visitas sociais, apadrinhamentos e viagens conjuntas.

Este seleto grupo de amigos ajuda a configurar aquilo que chamamos aqui de "proximidade": "bolha"; "microesfera"; forma particular de intimidade para criação de espaços ou "continentes autógenos" (SLOTERDIJK, 2016, p. 90). O valor que o casal Rosa-Aracy dava às bolhas da amizade, "imbricações, reflexões e ressonâncias" contidas nesses pequenos encontros sociais, revela o valor mesmo da proximidade: "coexistir em correspondência recíproca" ou modo de relação de uns com os outros, coexistindo, mediante as identificações e as "incorporações" (ibidem), assim como as interações nos "espaços íntimos partilhados, cossubjetivos e interinteligentes" (ibidem).

Na comunicação, salienta Sloterdijk (2016), não podemos deixar de atentar para a importância dessas "bolhas" ou microesferas relacionais, espaços da cordialidade afetiva, campo interfacial e de relações magnetopáticas. ${ }^{13}$ Esses casais e seus espaços de convivialidade, contornam, formam e determinam a dimensão afeto-comunicativa que subscreve, hoje, a figura sóciocultural de João Guimarães Rosa. A proximidade deles com o escritor mineiro ajuda a entender as "regiões" (HEIDEGGER, 2004) de envolvimento do ser, a "aproximação"14 ou as formas espaciais autoenvolventes, como as "soleiras"

12 Na qualidade de maior crítico da época, diretor do Suplemento Literário, redator-principal e dirigente político do Correio da Manhã (de 1940 a 1956), Álvaro Lins foi um dos responsáveis pelo rápido reconhecimento do estreante João Guimarães Rosa. A partir de seu artigo, várias outras críticas foram publicadas sobre Sagarana.

13 Propriamente o magnetismo das relações de proximidade exercidas mediante o "pathos", neste caso, a simpatia expressa ou não pelas formas do rosto, a força do olhar, a presença de espírito, o tirocínio, o tom da voz, enfim, as formas (ou "esferas") possíveis de comunicação emotiva. Vale registrar ainda que Sloterdijk (2016) busca neste estudo uma "filosofia dos meios de comunicação" mediante a investigação de uma "História social das práticas de proximidade" (p. 464) aliada a uma "Crítica da razão participativa" (p. 474).

14 Para Alexandre Costa, em comentário à tradução dos fragmentos do filósofo grego Heráclito, a noção de "aproximação" (Fragmento 122), é algo para o qual "é preciso uma observação acerca do significado do verbo "amphisbatein" em grego: originalmente, significa "aproximar", "aproximar-se", porque composto de "amphis" (em torno a, ao lado de) e "batein" (andar, avançar, ir ao encontro de). Mas como "amphis" também significa "dual" e mesmo "separado em duas partes", o verbo também denota "contestar", "discutir" (HERÁCLITO, 2010, p. 185) 
ou "clareiras", enfim, os espaços do entre, aquilo que Rosa a seu modo chamaria de "Travessia", "Passagem", "Vereda" ou "Entremeio."15

Não podemos esquecer que foi Álvaro Lins quem indicou e apresentou Rosa ao editor José Olympio, em 1951, e que ele foi durante duas décadas um dos mais populares e prestigiados críticos literários do país. Após publicar editoriais denunciando a tentativa de golpe contra a posse de Juscelino Kubitschek como Presidente da República, Lins foi nomeado chefe da Casa Civil do novo governo, sendo sucedido no Correio da Manhã por outro grande amigo de Rosa, Franklin de Oliveira que, em 1956, tornou-se editorialista e crítico literário do jornal, a convite de Paulo Bittencourt. Quando Franklin de Oliveira passou a ser perseguido pela ditadura militar, após o Golpe de 1964, ficando sem condições sequer de comprar comida para alimentar a família, Rosa intercedeu em seu favor, com Antonio Olinto, que procurou, por sua vez, Paulo Bittencourt. Este sugeriu ao diretor-geral de $O$ Globo, Roberto Marinho, que contratasse Franklin como editorialista. Roberto Marinho atendeu o pedido, e, ao assumir a responsabilidade da contratação, acabou sendo cobrado pelo regime militar; respondeu ao Ministro da Justiça na época, Juracy Magalhães, com a célebre frase: "Dos meus comunistas, cuido eu". ${ }^{16}$

\section{"Antijornalista", sensação de angústia e aversão às entrevistas}

Em duas ocasiões, ao ser questionado sobre seu sentimento em relação ao jornalismo, Guimarães Rosa citou a palavra "angústia" (BLOCH, 1963; BANDEIRA, 1966). Em contrapartida, em outro momento, em entrevista concedida a uma jovem estudante de 15 anos, sobre o compromisso de entregar quinzenalmente pequenos contos para o Pulso, afirmou que a sensação era a de criar um "bordado delicado" (ROSA, 1965, entrevista a Maria da Graça Faria Coutinho). Outro grande amigo, Paulo Rónai, que não era jornalista, chegou a ponderar, na nota de introdução a Tutameia, que o escritor mineiro referia-se à obra como da "maior importância" - o livro reúne histórias publicadas no jornal Pulso. Por isso, vemos que Guimarães Rosa parece manter uma relação de ambiguidade com o campo jornalístico, oscilando entre a proximidade (aventura de tecer "bordado delicado"), a inquietude e a inadequação, por isso mesmo compreendemos que Walnice Galvão tenha bem assimilado este último aspecto ${ }^{17}$, mas não a integralidade e a complexidade dessas "imbricações".

15 Tratamos anteriormente o tema dos "entremeios", noção explorada no conto Com o Vaqueiro Mariano (1952) e no romance Grande Sertão: Veredas (1956) no artigo: "Aspectos do imaginário e da Comunicação em Grande sertão: Veredas" Disponível em: http://seer.ufrgs.br/index.php/intexto/article/view/70932

16 Esse episódio é relatado por João Roberto Marinho, filho de Roberto Marinho, no documentário "Roberto Marinho: o senhor do seu tempo", Disponível em: https://www.youtube.com/watch?v=MqZWL5WcEYQ. Acess0 em: 15/01/2018.

17 Assim como sabemos que ela compreendeu de forma magnífica e excepcional os aspectos centrais da obra de Rosa, entre eles a própria noção de "ambiguidade", "princípio organizador" de Grande sertão: Veredas. Sobre a "ambiguidade" (GALVÃO, 1986). 
A proximidade e o afeto com o campo da comunicação, e mais particularmente com o jornalismo, remontava até mesmo à infância, quando, segundo as lembranças de sua filha Vilma Guimarães, o pai brincava de ser jornalista: "Uma de suas diversões foi o jornalismo caseiro. Publicava jornaizinhos, sendo responsável por todas as seções, as ilustrações e a distribuição entre as crianças da Família. E também era o tesoureiro" (ROSA, 2014, p. 43).

Guimarães Rosa confidenciaria ao amigo Manuel Bandeira, igualmente escritorjornalista, que sua relação com o jornalismo era de "angústia". Era 1961 e Bandeira reportou o episódio na crônica Rosa em Três Tempos (BANDEIRA, 1966). Bandeira revelou-se incomodado com o compromisso firmado por Rosa com $O$ Globo, para o qual escreveria, semanalmente, um artigo para a coluna Porta de Livraria, do escritor, jornalista e crítico Antonio Olinto. Bandeira conta que perguntou a Rosa como se sentia diante dessa obrigação, e ouviu como resposta: "Angústia!". Segundo o poeta, o escritor mineiro acrescentou que o espaço restrito do jornal não comportava o tamanho de sua imaginação. "Escrevo cinco, dez, quinze páginas. É preciso reduzir a três."

\begin{abstract}
Começo a escrever, um mundo de coisas, ideias, imagens, reminiscências, me acodem. Escrevo cinco, dez, quinze páginas. É preciso reduzir a três. Começo a cortar, começo a corrigir. O meu desejo é então continuar a corrigir até o fim da minha vida. Mas há que entregar os originais. E no dia seguinte, recomeçar coisa nova (ROSA apud BANDEIRA, 1966, p. 319).
\end{abstract}

É sintomático que dois anos depois, em 1963, Rosa tenha voltado a mencionar o sentimento de "angústia" em sua relação com o jornalismo em uma quase-entrevista concedida a Pedro Bloch para a revista Manchete, dizendo que "Jornal é angústia concentrada" (ROSA, 1963): "[...] detesto o cotidiano. Pra mim é um suplício comer, fazer a barba, vestir. O todo-dia é um inferno. Não leio jornal na hora. Jornal é angústia concentrada. Só leio matutino à noite... pra dar distância" (ibidem).

Com efeito, o resultado do compromisso de oito meses com O Globo foram as obras Primeiras estórias (1962) e Tutameia (1967), que reúnem a maioria dos textos publicados neste periódico. Vários textos produzidos para a coluna de O Globo foram considerados preciosidades pelos críticos, começando por A terceira margem do rio (15/4/1961). Outras relíquias publicadas ali foram: Sorôco, sua mãe, sua filha (18/3/1961), Os irmãos Dagobé (10/6/1961) e A menina de lá (6/5/1961), selecionados pelo próprio Rosa para Primeiras estórias (1962).

Desta presença e proximidade com o campo jornalístico, Rosa apreendeu a satisfação com o "exercício de despojamento", como definiu sua colaboração quinzenal para Pulso; e a busca da palavra "justa". Sabemos que este "exercício de despojamento" não podia deixar de contrastar com as noções de infinito, de eternidade e de texto difícil (BOLLE, 2004). Elas indispõem o escritor com a obrigação do limite espaço-tempo do jornalismo. Ao tradutor de sua obra para o italiano, Edoardo Bizzarri, chegou mesmo a definir-se 
como o "antijornalista": "Eu não improviso coisas escritas, sou lento, atormentado, sou o anti-jornalista. Tenho, apenas, boa vontade. E preciso respirar ainda um pouco, ganhar pé, sair do brejo. Sei que você está comigo, me compreende" (ROSA, 1965).

Rosa havia explicado a Pedro Bloch que não gostava de dar entrevistas pelo contraditório entre o imediatismo das respostas e o seu apreço pela eternidade. "Não gosto do transitório, do provisório. Gosto do eterno":

Você sabe por que não dou entrevista? Não é por vaidade, por nada. No começo, quando eu não era ninguém, ninguém queria entrevistar-me. Depois, com o começo de minha carreira literária, com Sagarana, começaram a entrevistarme. As entrevistas saíam e eu guardava. Não tenho nada contra quem entrevista. Tenho é contra mim. Passado tempo ia ver o que tinha dito e não concordava mais comigo. Não diria mais aquilo, compreende? Não gosto do transitório, do provisório. Gosto do eterno. (ROSA, 1963).

Entre a prática de proximidade e distância com o jornalismo, identificamos também a ambiguidade, confirmada em algumas posturas. Guimarães Rosa não demonstrava nenhuma satisfação em frequentar as redações ou em manter convívio com repórteres. Ao amigo e romancista Paulo Dantas, que tentou entrevistá-lo, ele foi enfático: "Não gosto do sentido bisbilhoteiro da imprensa. Ela deforma tudo. Irrita-me. Perco a naturalidade. Todas as vezes em que dei entrevistas, fiquei profundamente desgostoso com o que disse e com o que disseram de mim" (ROSA apud DANTAS, 1975).

A aversão aos jornalistas correu mundo. Em Gênova, em 1965, Günter Lorenz se congratulava de conseguir o acesso ao "inimigo de toda a espécie de entrevistas e terror dos repórteres". Rosa retrucou apontando a inutilidade das entrevistas: "As entrevistas são trocas de palavras em que um formula ao outro perguntas cujas respostas já conhece de antemão. Vim, como combinamos, porque desejávamos conversar. Nossa conversa, e isto é o importante, desejamos fazê-la em conjunto" (ROSA, 1965).

De modo semelhante, devemos retomar e aprofundar aqui a ideia e o interesse do escritor pelas dinâmicas interativas da conversação, diálogos e "entrevistas", que apreendia para si e para sua narrativa. Perguntador contumaz, uma de suas fontes recorrentes era o próprio pai, Florduardo Pinto Rosa, juiz de paz e comerciante abastado. Diante de seu armazém paravam moradores de Cordisburgo, viajantes, tropeiros, vaqueiros, enxadeiros, fazendeiros, entre outros, para reabastecimento. Rosa, ainda criança, costumava ouvir os causos dos viajantes e dos moradores que passavam por lá. Por isso, uma das fontes mais fidedignas para recolha de suas histórias era justamente o pai, Florduardo, a quem escrevia verdadeiras "cartas-questionários" (COSTA, 2002), demandando lembranças de Cordisburgo (MG) ${ }^{18}$, que servissem de munição para suas histórias. Chama a atenção que em uma dessas cartas, escrita a 27 de outubro de 1953, Rosa praticamente entrevista

18 Cidade natal de Guimarães Rosa, no centro-oeste de Minas Gerais. 
o pai, envia-lhe uma lista de assuntos a "esmiuçar", pedindo que as respostas sejam as mais minuciosas possíveis:

Há outros assuntos que gostaria de esmiuçar. Por exemplo: 1) A briga do Túlio com o Nicão - com os possíveis detalhes sobre a questão do terreno; 2) Descrição de pessoas da roça, as mais interessantes, que vinham à venda em Cordisburgo; 3) Descrição de pescarias, a rede; 4) Jogos de baralho: o truque, a "pavuna", no restaurante em Cordisburgo; a intervenção do Vigário, a briga do Sr. Gastão, com o padre; 5) Chico Sanfona, sua família, coisas interessantes que lhe digam respeito; 6) O Renério, idem; 7) As donas daquele sobradinho na Várzea, em Cordisburgo, idem; 8) Aquelas grandes quantidades de peixes de Pirapora (?), como o Sr. os comprava, como vinham, etc.; 9) Caixeiros-viajantes, interessantes ou curiosos, alguns bons traços; 10) Coisas interessantes, biográficas ou outras, sobre pessoas como: tio Adonias; o Siô Tico e Nhá Chica; o pai do Juca Saturnino; Siô Lé; Luiz Canabrava; aquele Sr. Nalesherbes, meio esquisito, que passou por Cordisburgo; etc.; 11) Esta é com ajuda de Mamãe: A história daquele corpo de homem, mumificado, que se desenterrou, em Jequitibá, e foi levado para a igreja; 12) Histórias de crimes, grandes brigas, raptos de moças, etc. (ROSA apud ROSA, 2014, p. 278-279).

Por fim, devemos destacar que uma das questões na literatura de Rosa é a presença de "entrevistas" subjacentes (como as realizadas no romance Grande Sertão: Veredas, e nos contos "Meu tio, o lauaretê" e "Entremeio: Com o vaqueiro Mariano"), como efeitos dialógicos. Na nota introdutória a Estas estórias, é sintomático que Paulo Rónai chame de "entrevista-retrato" o perfil de Mariano. Nestes textos, vemos um "monólogo inserto em situação dialógica" (SCHWARZ apud BOLLE, 2004, p. 40). A quase-entrevista ou a semi-entrevista é a técnica utilizada para o compartilhamento tácito do mediador com o ouvinte e vice-versa. Neste compartilhamento, o interlocutor (de Riobaldo, por exemplo) quer entender como e por que um sertanejo semiletrado, ex-jagunço, assimilou, aprendeu e se colocou complexas e sofisticadas questões de ordem filosófica e existencial. A entrevista aparece aqui com a capacidade de mediar testemunhos, com ou sem críticas e julgamentos, diante da abertura à escuta do outro.

\section{Conclusão - proximidades e distanciamentos}

No sentido de exercício didático da prática de proximidade com o jornalismo que correspondeu a 1) identificações e "incorporações, invasões, imbricações, reflexões e ressonâncias" (SLOTERDIJK, 2016, p. 90), com o campo jornalístico e mediante 2) as interações com os "espaços íntimos partilhados, cossubjetivos e interinteligentes" entre esses mesmos grupos, formados por amigos, editores, críticos, chefes de redação, colunistas, membros do Itamaraty e da Academia Brasileira de Letras (ABL), assim como 3) 
os textos publicados em veículos controlados por membros desses mesmos grupos, enfim, todas essas atividades e referências formam alguns dos principais canais de acesso ao entendimento da relação de Guimarães Rosa com o jornalismo. Sua "angústia" e aparente busca por distanciamentos do universo jornalístico fazia parte de um planejamento de sua própria imagem, como revelou em carta (citada) a Álvaro Lins: "não me exponho, a não ser por deliberado projeto" (ROSA, 1950).

Verificamos, portanto, um movimento ambíguo, de proximidade e distanciamento estratégico, apuro no cálculo, planejamento e articulação de suas relações e movimentos para com a imprensa carioca e paulista. Identificamos em Guimarães Rosa, entre 1947 e 1967, nesta relação de ambiguidade para com a imprensa, um misto de afeto e interesse, angústia e desconforto. Antes mesmo de 1947, com a publicação de quatro contos na revista O Cruzeiro e em O Jornal (RJ), a título de capitalização monetária, em 1929 e 1930. O mesmo ocorreu com a revista Senhor. Vimos uma relação de presença e proximidade do escritor com vários jornais e dois compromissos assumidos com os jornais O Globo e Pulso.

Rosa escreveu contos, crônicas e poemas publicados em jornais e revistas de grande prestígio. O jornalismo fazia parte 1) de suas conversas funcionais (como alto membro do corpo diplomático) e no dia-a-dia, como amigo íntimo de editores e chefes de redações e 2) de suas conversas ficcionais. Entre 1947 e 1967, o escritor mineiro publicou 122 histórias, uma média de 6 textos por ano, durante vinte anos. Galvão equivoca-se ao falar em uma "insignificante média de duas a três matérias por ano" (GALVÃO, 2008, p. 219). Tendo em vista que seus textos não eram meros relatos jornalísticos, mas criações artísticas, escritas à maneira de contos, crônicas, poemas e "reportagens poéticas", essa dificuldade criativa nos parece ainda maior.

Por tudo isso, não podemos aferir que, para Rosa, "o jornalismo não [tinha] a menor importância". Afora isso, Rosa apreendeu técnicas mediante a leitura de jornais e ruminou a entrevista como "situação dialógica", vendo-a como estratégia narrativa, mas também como algo incômodo e dificultoso e compreendeu o repórter em seu sentido "bisbilhoteiro". Essas "situações dialógicas" aparecem de maneira estruturante no livro Grande Sertão: veredas, assim como nos contos Meu Tio, lauaretê e na "entrevista-retrato" Com o vaqueiro Mariano. Vimos que a percepção ética, estética e estratégica de Rosa para com a prática jornalística e seus atores, assim como algumas marcas do jornalismo em sua literatura, são alimentadas pelo estímulo financeiro; a garantia de visibilidade e proximidade do público leitor e de amigos pessoais em cargos editoriais.

Gustavo Castro é professor de Estética no Programa de Pós-Graduação em Comunicação da Universidade de Brasília (UnB). É jornalista, antropólogo, poeta e escritor.

gustavodecastro@unb.br 
Andrea Jubé é jornalista e mestre pelo Programa de Pós-Graduação em Comunicação da Universidade (UnB).

andreajubevianna@gmail.com

\section{Referências}

BANDEIRA, M. Andorinha, Andorinha. Rio de Janeiro: José Olympio Editora, 1966.

BOLLE, W. Grande sertão: Br. São Paulo: Editora 34/Duas Cidades, 2004.

CADERNOS de Literatura Brasileira. João Guimarães Rosa. São Paulo: Instituto Moreira Salles. N. 20/21, dez. 2006.

COSTA, A. L. M . João Guimarães Rosa Viator. 2002. 270f. Tese (Doutorado em Letras). Instituto de Letras Universidade Estadual do Rio de Janeiro.Rio de Janeiro: p. 67-68. 2015.

DANTAS, P. Sagarana emotiva. São Paulo: Livraria Duas Cidades, 1975.

GALVÃO, W. N. As formas do falso. São Paulo: Ed. Perspectiva, 1986.

. Mínima mímica. São Paulo: Companhia das Letras, 2008.

. Mitológica Rosiana. São Paulo: Ed. Ática, 1978.

Guimarães Rosa. São Paulo: Publifolha, 2000.

GAMA, M. F. R. Plástico e contraditório rascunho: a autorrepresentação de João Guimarães Rosa. 2013. 330f. Tese (Doutorado em Letras). Faculdade de Filosofia, Letras e Ciências Humanas, Universidade de São Paulo. São Paulo: 2013.

HEIDEGGER, M. A Caminho da linguagem. Trad. Márcia Sá Cavalcanti Schuback. Petrópolis: Ed. Vozes, 2004.

HERÁCLITO. Fragmentos contextualizados. Tradução, notas e organização Alexandre Costa, São Paulo: Difel, 2010, p. 185.

PEREIRA, O. S. "Guimarães Rosa segundo terceiros". Realidade, São Paulo, Ed. Abril, ano 2, n. 16, p. 58-61 e 70, julho de 1967.

RESENDE, O. L. O príncipe e o sabiá e outros perfis. 2 ed. São Paulo: Companhia das Letras, 2017.

ROCHE, D. História das coisas banais - Nascimento do Consumo nas Sociedades do Século XVII ao XIX. Lisboa: Relógio D'água, 2000.

ROSA, J. G. Ave, Palavra. 5 ed. Rio de Janeiro: Nova Fronteira, 2001a.

Carta a Edoardo Bizzarri. [7 mar. 1965].

Carta a Álvaro Lins [19 fev. 1950]. Disponível em: http://www1.folha.uol.com.br/ fsp/1995/6/04/mais!/11.html . Acesso em 26 nov. 2017.

Entrevista a Günter Lorenz no Congresso de Escritores Latino-Americanos, em Gênova, janeiro de 1965. In: Diálogo com a América Latina. São Paulo: E.P.U, 1973.

. Entrevista a Maria da Graça Faria Coutinho. Rio de Janeiro, 1965. Disponível em http:// www.letras.ufrj.br/olacdigital/?p=1241 Acesso e 26 nov. 2017.

Entrevista a Pedro Bloch. Rio de Janeiro: Revista Manchete. n. 580, 1963.

. Estas estórias. 8 ed. Rio de Janeiro: Nova Fronteira, 2015. 
Há títulos e brasões também no mundo dos bichanos. Rio de Janeiro: Flan. Entrevista a Carlos Rocha Rarfa de Laet, 1953.

Primeiras estórias. 15. ed. Rio de Janeiro: Nova Fronteira, 2001 b.

Tutameia (Terceiras histórias). 9. ed. Rio de Janeiro: Nova Fronteira, 2009.

ROSA, V. G. Relembramentos: João Guimarães Rosa, meu pai. 4 ed. Rio de Janeiro: Nova Fronteira, 2014.

SLOTERDIJK, P. Esferas 1. Bolhas. Trad. José Oscar de Almeida Marques. São Paulo: Ed. Estação Liberdade, 2016.

Artigo recebido em 06/04/2018

e aprovado em 02/05/2018. 